\title{
КЛАСИФІКАЦІЯ НОРМА/ПАТОЛОГІЯ ПРИ ДИФУЗНИХ ЗАХВОРЮВАННЯХ ПЕЧІНКИ ЗА ОЗНАКАМИ ТЕКСТУРИ УЛЬТРАЗВУКОВИХ ЗОБРАЖЕНЬ ЗІ ЗМЕНШЕНОЮ КІЛЬКІСТЮ ВІДТІНКІВ СІРОГО
}

\author{
Шулигін Д.Е., бакалавр \\ shulygin.d@gmail.com \\ Настенко С.А., к.т.н., д.б.н., ст.н.с. \\ nastenko.e@gmail.com \\ Кафедра біомедичної кібернетики \\ Національний технічний університет України \\ «Київський політехнічний інститут імені Ігоря Сікорського» \\ м. Київ, Україна
}

\begin{abstract}
Реферат - Створено алгоритми для нормалізаџї зображення, зменшення кількості відтінків, виділення регулярної частини зображення. Розроблено програмний додаток з використанням мови програмування $C++$ та фреймворку Qt. Проаналізовано результати обробки зображень шляхом побудови графіків розподілу відтінків сірого, зменшення кількості відтінків сірого та виділення регулярної / іррегулярної частини.
\end{abstract}

Ключові слова - ультразвукова діагностика, обробка зображень, аналіз текстури, системи підтримки прийняття рішень, C++, Qt 5 .

\section{I. ВСТУП}

Захворювання паренхіматозних органів, зокрема легень та печінки, - $є$ одними 3 найпоширеніших захворювань на планеті. Дифузні ураження печінки часто спостерігаються у дітей та потребують ретельного дослідження на всіх етапах діагностики та лікування. Найчастіше такі захворювання розвиваються непомітно i протікають безсимптомно. Вони можуть непомітно прогресувати в цироз, найяскравішими прикладами таких захворювань $\epsilon$ вірусні гепатити.

Найточніший метод діагностики захворювань печінки - проведення біопсії, але при проведенні біопсії з'являються такі ризики як біль, кровотеча, інфекція, травмування сусідніх органів[1].

Тому найрозповсюдженішим методом неінвазивної діагностики дифузних захворювань печінки $\epsilon$ ультразвукове дослідження (УЗД), яке інтенсивно удосконалюється останнім часом[2].

Одним із методів аналізу даних УЗД $є$ текстурний аналіз, тобто виявлення структурних змін тканин під впливом патологічного процесу, та(або) лікувальних заходів $[3,4]$.

Відомі різні підходи до виявлення текстури тканин, проте застосування підходів теорії інформації, зокрема кількісних оцінок алгоритмічної складності за А.Н. Колмогоровим, $\epsilon$ досить перспективним i наразі представлене недостатньо.

\section{II. МЕТА ДОСЛІДЖЕННЯ}

Для роботи використані 10 фрагментів УЗД зображень печінки у нормі та 6 фрагментів при цирозі печінки у дітей віком від 9 до 11 років, отримані за допомогою лінійного УЗ датчика в режимі збільшеного масштабу.

Обробка зображення базувалася на зменшенні кількості відтінків сірого та 
побудові матриці суміжності. Тобто, обчислювалась кількість повторів відтінків сірого двох сусідніх точок зображення. Найбільш повторювані комбінації складали регулярну складову зображення, більш рідкісні сполучення відтінків сірого - iї іррегулярну складову.

\section{II. НОРМАЛІЗАЦІЯ ЗОБРАЖЕНЬ}

На початку маємо зображення текстури печінки норми і цирозу у вигляді, наведеному на рис. 1, 2:

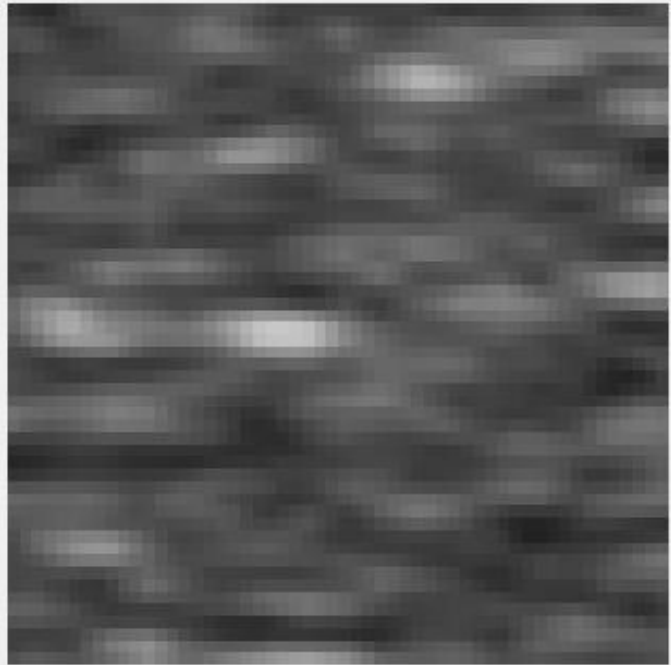
печінки.

Рис. 1. Вихідне зображення для здорової

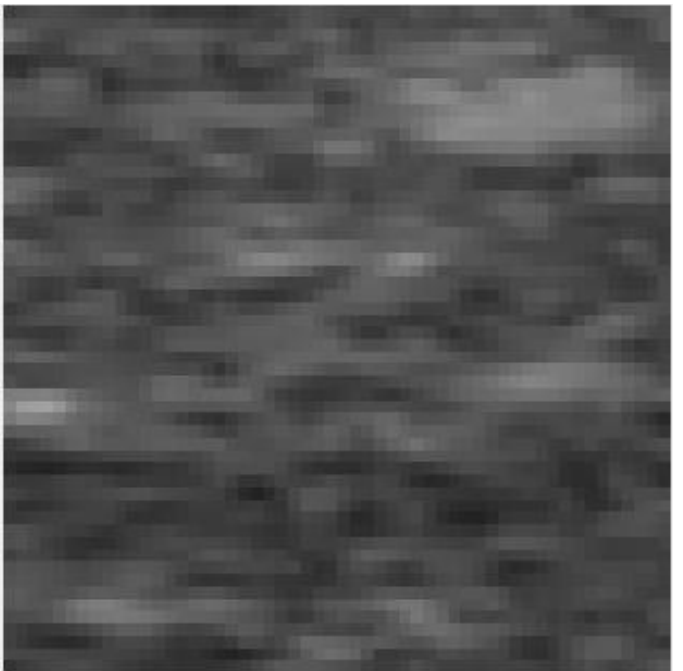

Рис. 2. Вихідне зображення для печінки з цирозом.

Для підвищення наочності текстури печінки на ЧБ зображенні та для уникнення проблем через різні налаштування яскравості і контрастності на апараті УЗД, отримані зображення слід нормалізувати[5]. Це можна зробити представивши вихідне зображення у вигляді двовимірної числової матриці i перерахувавши кожне ії̈ значення за формулою:

$\mathrm{C}=($ Cprev-min $) *(255 /(\max -\min ))$,

де Cprev - початкове значення в клітинці, min найменше значення градації сірого, а max найбільше.

Таким чином, усі зображення було нормалізовано, внаслідок чого найсвітліший відтінок для кожного з них було перетворено на білий, а найтемніший - на чорний. Отримані на цьому етапі зображення мають наступний вигляд:

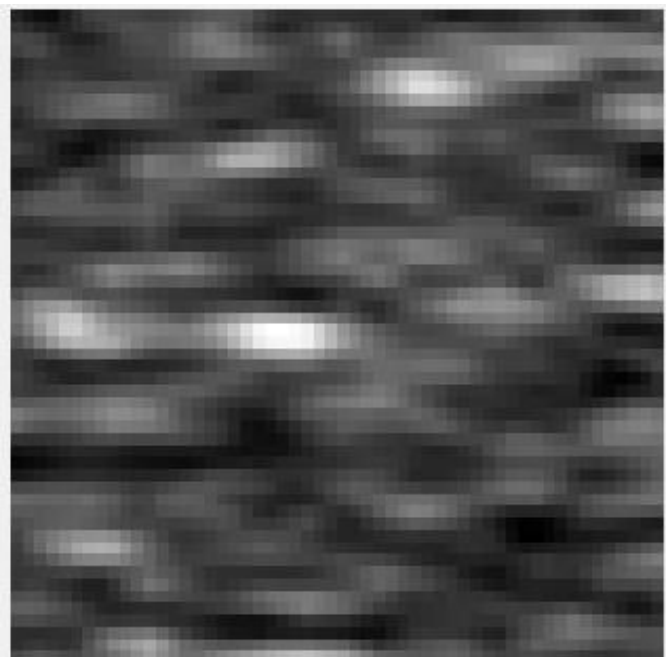

Рис. 3. Нормалізоване зображення для здорової печінки.

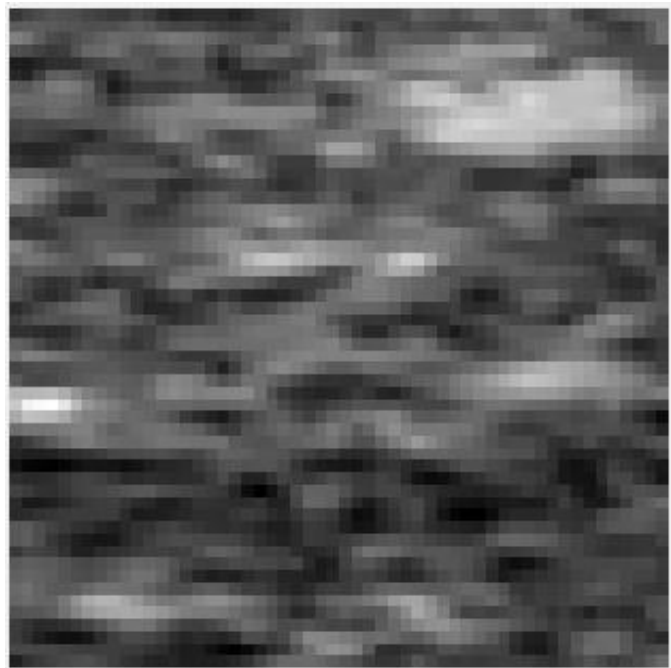

Рис. 4. Нормалізоване зображення для печінки з цирозом.

Для подальшого покращення візуалізації текстури було вирішено зменшити кількість відтінків сірого на зображенні. Після такої обробки маємо: 


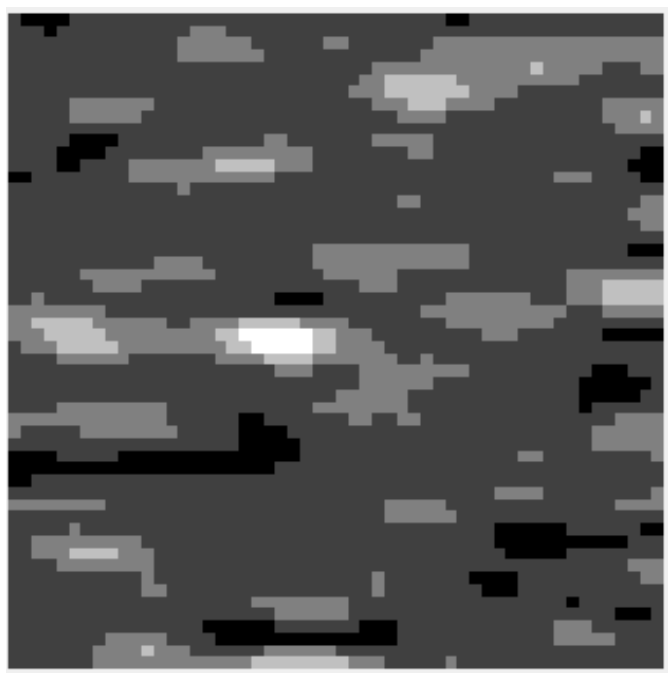

Рис. 5. Зображення зі зменшеною до 5 кількістю відтінків сірого для здорової печінки.

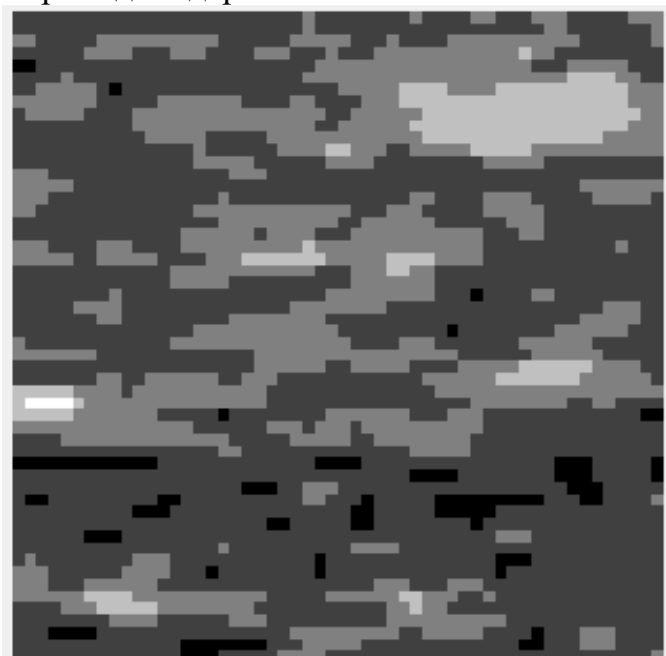

Рис. 6. Зображення зі зменшеною до 5 кількістю відтінків сірого для печінки з цирозом.

На даному етапі вже добре помітно різницю між зображеннями - на зображенні для норми текстура є більш однорідною, а для цирозу видно вищу зернистість зображення, горизонтальні послідовності одного відтінку в середньому коротші.

\section{IV. ДІАГРАМИ РОЗПОДІЛУ ВІДТІНКІВ СІРОГО}

Для отримання додаткової інформації було побудовано гістограми розподілу відтінків сірого для нормалізованих зображень, рис.7.А, 8.А, і зображень 39 відтінками сірого, рис. 7.Б, 8.Б, отримаємо:
Color distribution in the normalised picture:
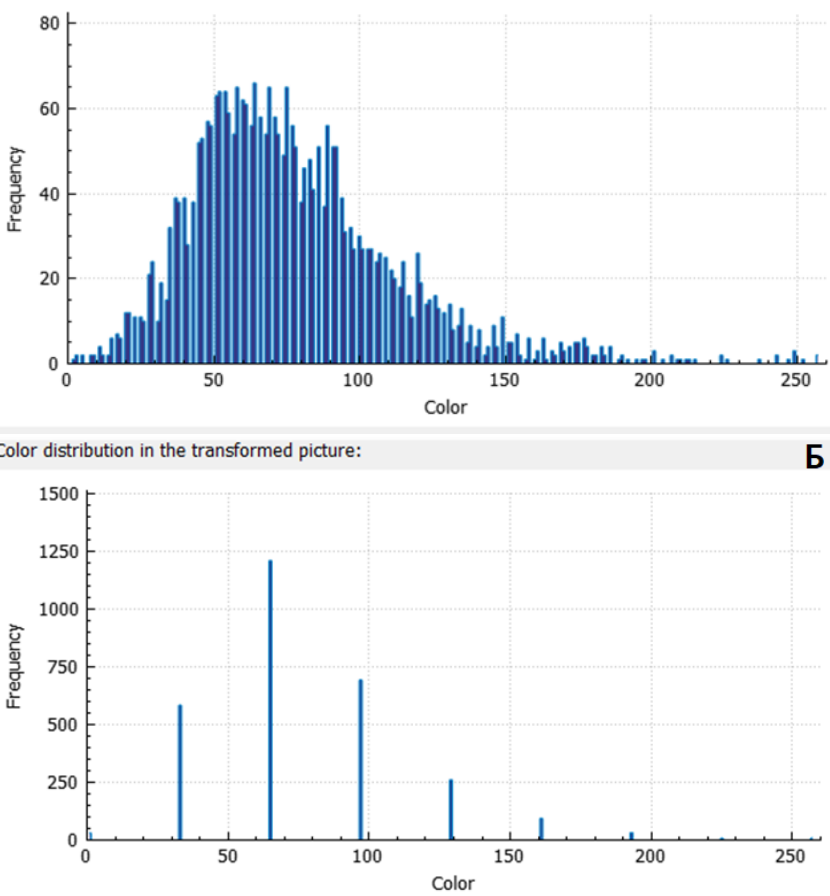

Рис. 7. Розподіл відтінків сірого на текстурі здорової печінки: А) нормоване зображення, Б) зображення з 9 відтінками сірого.

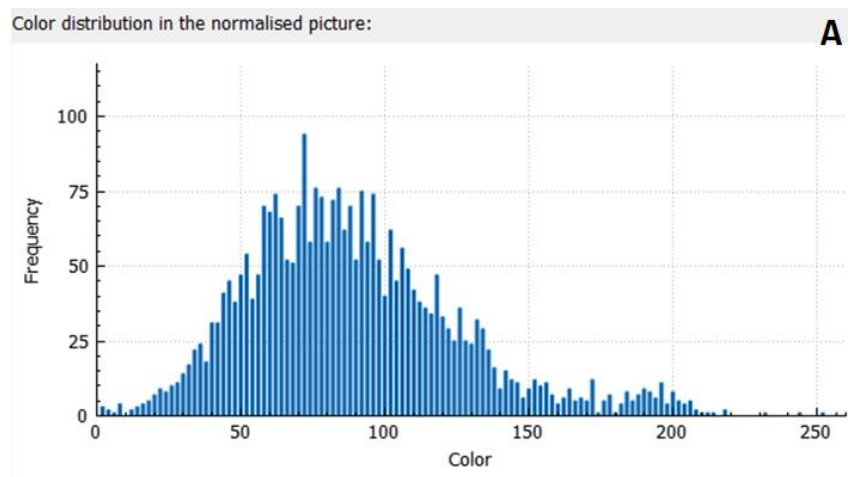

Color distribution in the transformed picture:

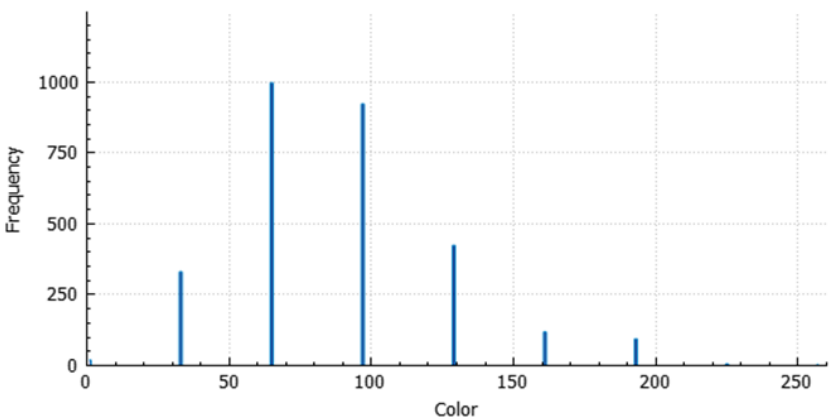

Рис. 8. Розподіл відтінків сірого на текстурі печінки 3 цирозом: А) нормоване зображення, Б) зображення з 9 відтінками.

Помітно, що для печінки 3 цирозом частіше зустрічаються більш світлі відтінки. Також, медіани гістограм розподілів при 9 відтінках сірого становлять: 1208 для норми, а для цирозу - 997, в обох випадках на одному відтінку -64 . 


\section{V. МАТРИЦІ СУМІЖНОСТІ}

На наступному етапі дослідження були побудовані матриці суміжності зображень[6].

У кожному випадку була отримана двовимірна числова матриця, яка відображає, наскільки часто на зображенні зустрічається відповідна кожній комірці пара відтінків сірого[7]. Таку матрицю можна представити у вигляді карти кольорів. Чим комірка в матриці світліша, тим частіше відповідна ій пара пікселів зустрічається на зображенні текстури, рис. $9,10$.

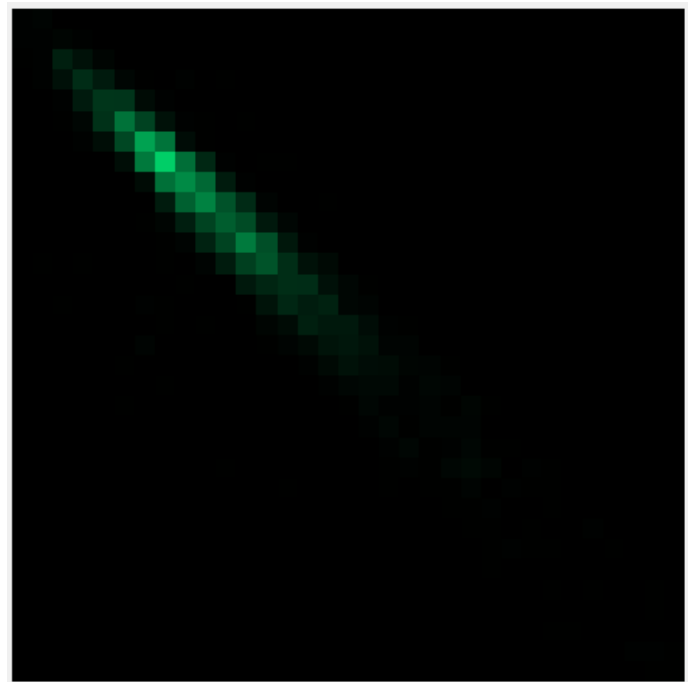

Рис. 9. Матриця суміжності для здорової печінки при 33 відтінках сірого.

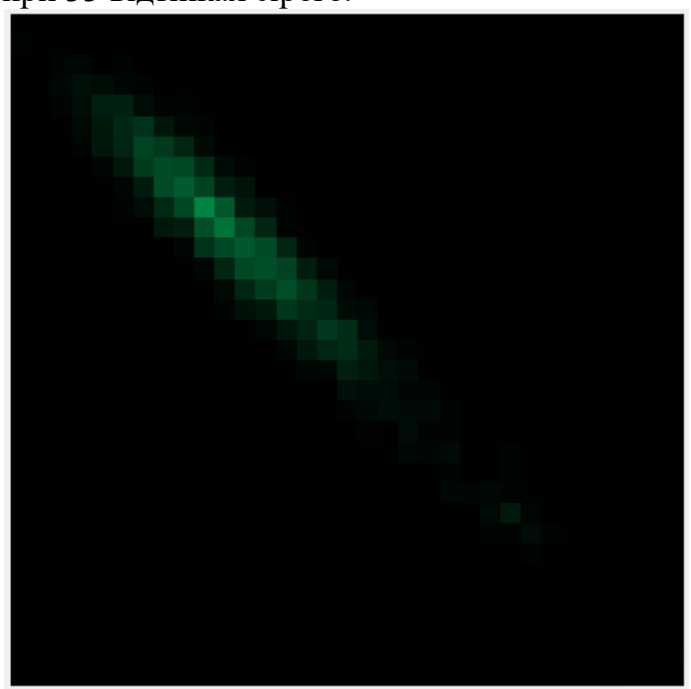

Рис. 10. Матриця суміжності для печінки 3 цирозом при 33 відтінках сірого.

За матрицею суміжності можна визначити регулярну (повторювану) та нерегулярну (мало повторювану) частини зображення. Для цього на матриці суміжності було визначено такі пари відтінків сірого, які зустрічаються на зображенні найчастіше (рідше за все). На рис. 11, 12 наведено текстури 3 позначеною фіолетовим регулярною частиною для печінки у стані норми та цирозу відповідно.

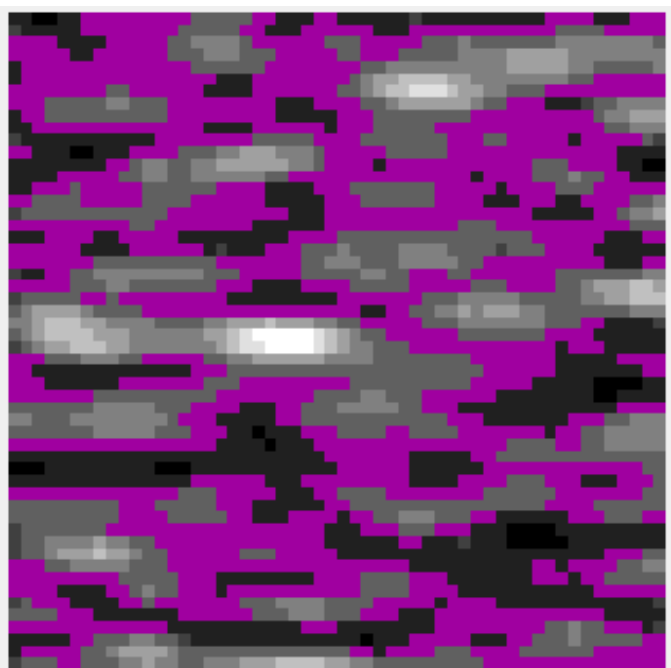

Рис. 11. Зображення 3 позначеною регулярною частиною для зображення 39 відтінками сірого i текстурою здорової печінки.

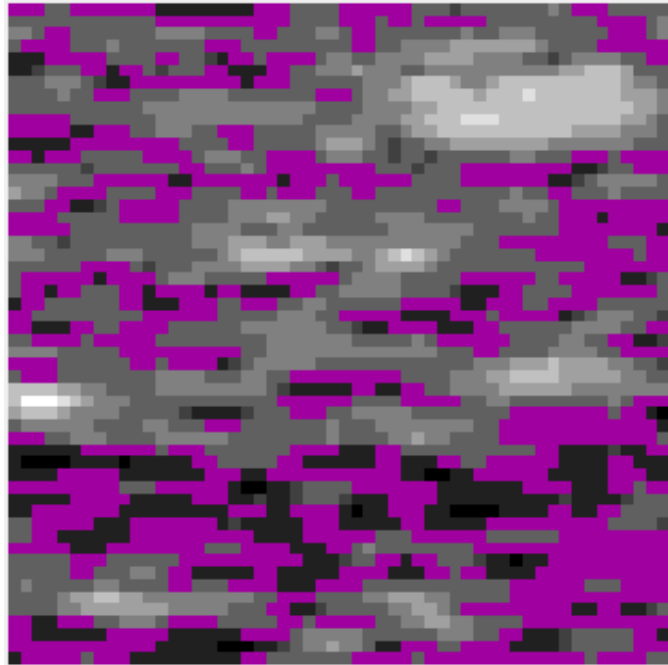

Рис. 12. Зображення 3 позначеною регулярною частиною для зображення 39 відтінками сірого i текстурою печінки з цирозом.

На рис. 13, 14 показано текстури 3 позначеною фіолетовим нерегулярною частиною для печінки у стані норми та цирозу відповідно. Нерегулярну частину зображення було розраховано як залишок від регулярної частини. 


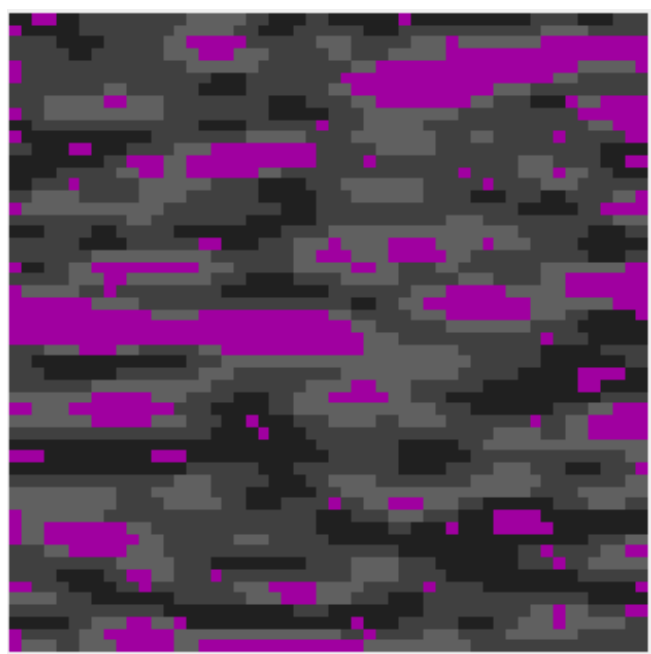

Рис. 13. Зображення 3 позначеною нерегулярною частиною для зображення з 9 відтінками сірого і текстурою здорової печінки

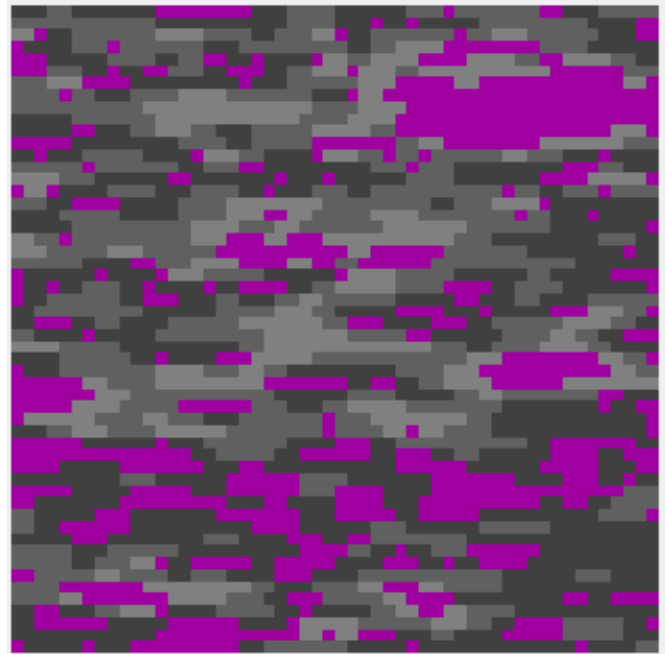

Рис. 14. Зображення 3 позначеною нерегулярною частиною для зображення з 9 відтінками сірого і текстурою печінки з цирозом.

Видно, що через зсув точок зображення у зону більш світлих відтінків текстури внаслідок більшої ехогенності тканини печінки 3 цирозом, найтемніші ділянки були визначені для неї як нерегулярна частина, тому, як видно на рис. 14, їх було позначено фіолетовим кольором.

\section{VI. ЗАКЛЮЧЕННЯ}

1. Використовуючи зменшення кількості градацій на зображенні текстури печінки можна досягти значного підвищення якості візуалізації меж на текстурі печінки у нормі та при цирозі, що є цінним для підтримки прийняття лікарем діагностичних рішень.

2. Додаткову цінну інформацію про ступінь пошкодження печінки можна отримати iз зображень 3 виділеною регулярною / нерегулярною частиною та 3 діаграм розподілу відповідних відтінків сірого на зображенні.
3.
Отримані
кількісні

характеристики регулярної та нерегулярної частин УЗД зображень можуть буті використані при створенні діагностичних систем автоматичної класифікації.

\section{ЗАСОБИ ВЗАЕМОДІї 3 ПРОГРАМНИМ ДОДАТКОМ}

Для взаємодії користувач а 3 додатком було передбачено наступні засоби управління (Рис. 15):

1. Кнопка для зміни вихідного зображення;

2. Повзунок для зміни кількості відтінків сірого;

3. Кнопка для відображення / приховання регулярної / нерегулярної частини;

4. Повзунок для вибору розміру регулярної / нерегулярної частини.

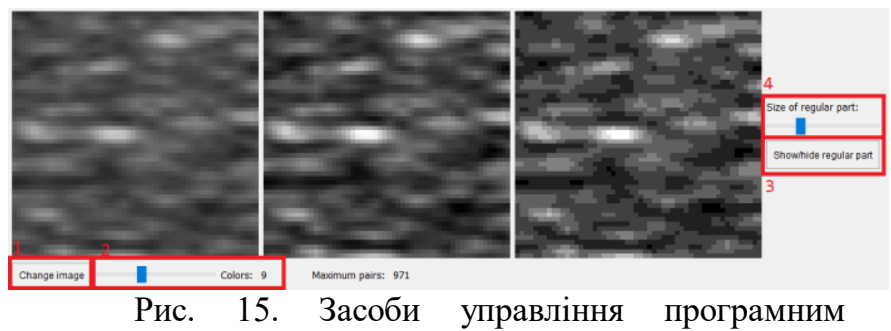
додатком.

В загальному випадку, інтерфейс додатку має наступний вигляд:

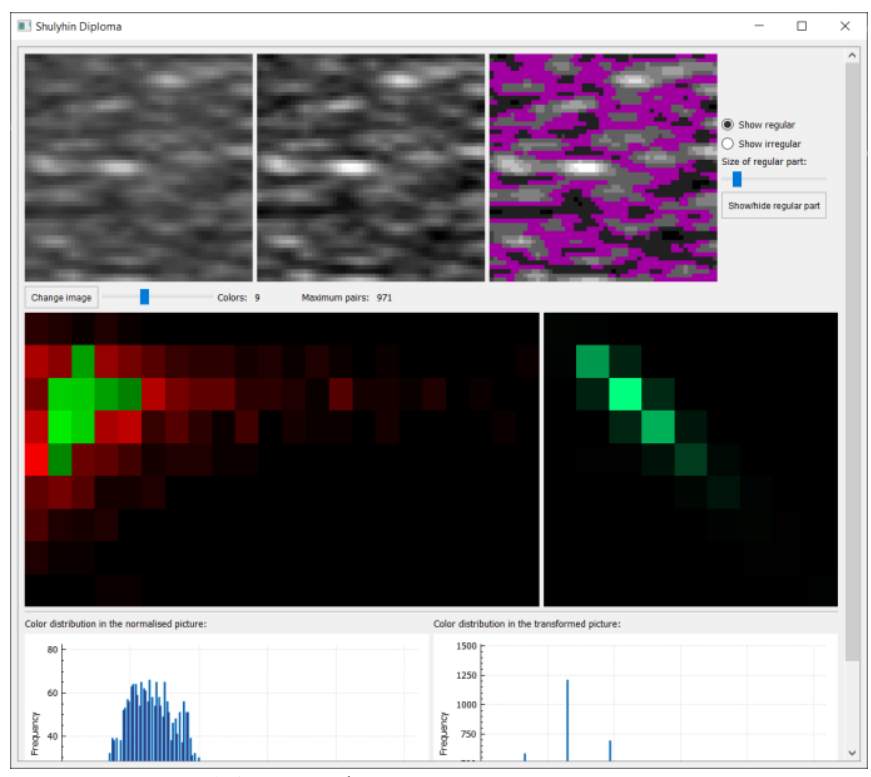

Рис. 16. Інтерфейс програмного додатку. 


\section{ПЕРЕЛІК ПОСИЛАНЬ}

[1] Liver Biopsy https://www.healthline.com

[2] Liver fibrosis, cirrhosis, and cirrhosis-related nodules: Imaging diagnosis and surveillance / C. Aubé, P. Bazeries, J. Lebigot, V. Cartier, J. Boursier

[3] УЗД печінки: підготовка, проведення та розшифровка результатів [Електронний ресурс] - Режим доступу: https://hemomedika-tyachiv.com
[4] Liver: structure and function. / Popper, Hans, and Fenton Schaffner 1957

[5] Texture Analysis Methods for Medical Image Characterization / William Henry Nailon

[6] The Linear Algebra Survival Guide / Fred E.Szabo 2015, 101 $118 \mathrm{c}$.

[7] Texture Analysis Based On The Gray-Level Co-Occurrence Matrix Considering Possible Orientations / Biswajit Pathak, Debajyoti Barooah

УДК 616.7

\title{
КЛАССИФИКАЦИЯ НОРМА/ПАТОЛОГИЯ ПРИ ДИФФУЗНЫХ ЗАБОЛЕВАНИЯХ ПЕЧЕНИ ПО ПРИЗНАКАМ ТЕКСТУРЫ УЛЬРАЗВУКОВЫХ ИЗОБРАЖЕНИЙ С УМЕНЫШЕННЫМ КОЛИЧЕСТВОМ ОТТЕНКОВ СЕРОГО
}

\author{
Шульгин Д.Э., бакалавр \\ shulygin.d@gmail.com \\ Настенко Е.A., к.т.Н., д.б.н., ст.н.с. \\ nastenko.e@gmail.com \\ Кафедра биомедицинской инженерии \\ Национальный технический университет Украины \\ «Киевский политехнический институт имени Игоря Сикорского» \\ м. Київ, Україна
}

\begin{abstract}
Реферат - Созданы алгоритмы для нормализации изображений, уменьшения количества оттенков серого, выделения регулярной части изображения. Разработано программное обеспечение с использованием языка программирования C++ u фреймворка Qt. Проанализированы результаты обработки изображений методом построения графиков распределения оттенков серого, уменьшения количества оттенков серого и выделения регулярной / иррегулярной части.
\end{abstract}

Ключевые слова - ультразвуковая диагностика, обработка изображений, анализ текстуры, системы поддержки принятия решений, $C++, Q t$ 


\title{
CLASSIFICATION OF NORM/PATHOLOGY IN DIFFUSE LIVER DISEASES ACCORDING TO THE TEXTURE OF ULTRASOUND IMAGES WITH A REDUCED NUMBER OF SHADES OF GRAY
}

Shulyhin D.E., Bachelor student shulygin.d@gmail.com

Nastenko E.A., Ph.D., Doctor of Biological Sciences, senior researcher nastenko.e@gmail.com

Department of Biomedical Engineering National Technical University of Ukraine "Igor Sikorsky Kyiv Polytechnic Institute" Kiev, Ukraine

\begin{abstract}
Algorithms for normalizing images, reducing the number of shades of gray, and highlighting the regular part of the image have been created. Software was developed using the $C++$ programming language and the Qt framework. The results of image processing by graphing the distribution of shades of gray, reducing the number of shades of gray and highlighting the regular / irregular part are analyzed.
\end{abstract}

Keywords - ultrasound diagnostics, image processing, texture analysis, decision support systems, C++, Qt 5 . 